\title{
Antimicrobial effects of various methods for the disinfection of contaminated toothbrushes.
}

\author{
Ah-Reum Shin, Seoul-Hee Nam* \\ Department of Dental Hygiene, College of Health Sciences, Kangwon National University, Samcheok-Si, Republic of \\ Korea
}

\begin{abstract}
This study aims to investigate the antimicrobial effect of the UV toothbrush sterilizer and various disinfectants on the toothbrush, urge the general public in recognizing the necessity of toothbrush disinfection, prevent oral diseases by disinfecting the toothbrush in a simple and cost effective way, and provide effective and proper hygiene management methods for toothbrushes. 20 female college students in Gangwon province were instructed to brush their teeth for 4 weeks. After 4 weeks of brushing their teeth, their toothbrushes were collected and soaked in $10 \mathrm{ml}$ of $0.2 \%$ chlorhexidine gluconate (CHX) solution for group I $(n=4), 10 \mathrm{ml}$ of $7.5 \%$ povidone iodine (PVI) solution for group II (n=4), and $10 \mathrm{ml}$ of sodium bicarbonate-normal saline solution for group III $(n=4)$. The bristles of the toothbrushes were immersed in each solution for 10 minutes. For group IV $(n=4)$, the toothbrushes were placed in a UV toothbrush sterilizer for 5 min and $30 \mathrm{~s}$ according to the instruction of the manufacturer. For group $\mathrm{V}$ $(\mathrm{n}=4)$, the toothbrushes were soaked in $10 \mathrm{ml}$ of sterile distilled water for $10 \mathrm{~min}$ as a control group. The experiment results showed that there were statistically significant differences among the 5 groups. Antimicrobial effects of toothbrushes in the experimental groups differed from those in the control group $(p<0.05)$. The antimicrobial effect on the toothbrush was most prominent in the groups treated with CHX and PVI disinfectants for $10 \mathrm{~min}$, followed by the UV toothbrush sterilizer and sodium bicarbonate-normal saline and sterile distilled water (control group). Therefore, $0.2 \% \mathrm{CHX}$ and $7.5 \%$ PVI disinfectants can be regarded as the best disinfectants in terms of their antimicrobial effect on the toothbrush, and they can also be recommended as proper toothbrush disinfectants in terms of cost effectiveness.
\end{abstract}

Keywords: Chlorhexidine gluconate (CHX), Povidone iodine (PVI), Sodium bicarbonate-normal saline, Ultraviolet (UV) toothbrush sterilizer, Toothbrush.

\section{Introduction}

The oral cavity forms an environment that various germs can inhabit. The dental plaque is a sticky glycoprotein film on the tooth surface, which is covered with oral bacteria, and there are approximately more than 500 kinds of bacterial aggregates. In the beginning, there are many cocci and filamentous fungi, but spirochetes and vibrios appear over time [1]. For this reason, the dental plaque should be removed instantly, and tooth brushing is recommended as the most effective and economical way of preventing oral diseases [2].

Tooth brushing is the most common method of oral hygiene management that plays an essential role in preventing dental caries and periodontal disease by removing the dental plaque on the tooth surface and appropriately stimulating the gingiva [3]. However, since toothbrushes of healthy or diseased persons contain a large number of pathogenic microorganisms, they can cause respiratory, gastrointestinal, cardiovascular, and kidney problems [4]. Moreover, the bristles contaminated with microorganisms resulting from daily use may cause a problem that can lead to oral infection [5]. One toothbrush has millions to billions of germs, and contamination occurs from the initial use of the toothbrush [6]. The more it is used repeatedly, the more it will be at risk for contamination [7].

According to the study of Verran [8], the total number of bacteria isolated from the toothbrush was $4 \times 10^{8} \mathrm{CFU} / \mathrm{ml}$, thereby showing various distributions of bacteria, including staphylococci $64 \%$, coliforms $57 \%$, pseudomonads $28 \%$, and yeast $39 \%$. Toothbrushes can be contaminated from storage environments, hand hygiene, air, and storage container [9]. In general, toothbrushes are stored primarily in a bathroom, which is an environment with a high contamination level due to the intestinal bacteria in the air [10]. Toothbrush disinfection is essential for oral cleaning and hygiene management of toothbrushes, along with physical health [11].

Currently, various studies for toothbrush disinfection have been actively carried out, including the use of a UV toothbrush 
sterilizer [12], disinfection by immersion [13], antimicrobial solution spray on bristles [14], microwave oven use [15], and dishwasher use [16]. Toothbrush disinfection should be fast, effective, cost effective, nontoxic, and easy to implement. There are only a few studies on toothbrush disinfection using a UV toothbrush sterilizer and various disinfectants.

Therefore, this study aims to investigate the antimicrobial effect of a UV toothbrush sterilizer and various disinfectants on the toothbrush, urge the general public in recognizing the necessity of toothbrush disinfection, prevent oral diseases by disinfecting the toothbrush in a simple and cost effective way, and provide effective and proper toothbrush management methods.

\section{Material and Methods}

\section{Study subjects}

This study was conducted on 20 female college students in Gangwon province, who had no special medication history within the last six months. The sample was composed randomly allocated to I IV group. The study purpose and methods were explained to the subjects, and the subjects, who gave their consent to the experiment, were instructed to brush their teeth for four weeks with the toothbrush provided by the research team.

\section{Disinfection for contaminated toothbrushes}

The toothbrushes were collected after 4 weeks, and 5 groups (I, II, III, IV and V) were randomly assigned four toothbrushes each. For group I $(n=4)$, the toothbrushes were soaked in $10 \mathrm{ml}$ of $0.2 \%$ chlorhexidine gluconate (CHX, hexamethine, Bukwang Pharmaceutical, Korea) solution for 10 minutes by submerging the bristles. For group II $(n=4)$, the toothbrushes were soaked in $10 \mathrm{ml}$ of $7.5 \%$ povidone iodine (PVI, Sungkwang Pharmaceutical, Korea) solution diluted 15-fold for $10 \mathrm{~min}$ according to the instruction of the manufacturer. For group III $(n=4)$, the toothbrushes were soaked in $10 \mathrm{ml}$ of sodium bicarbonate-normal saline solution for $10 \mathrm{~min}$, in which $20 \mathrm{~g}$ of sodium bicarbonate was mixed with $1 \mathrm{~L}$ of normal saline solution based on the method suggested in the study of Kim et al. [17]. For group IV $(n=4)$, the toothbrushes were placed in a UV toothbrush sterilizer (TBS-500/700, Iriver LTD, Seoul, Korea) for $5 \mathrm{~min}$ and $30 \mathrm{~s}$ according to the instruction of the manufacturer. For group V $(n=4)$, the toothbrushes were soaked in $10 \mathrm{ml}$ of sterile distilled water (D.W) for $10 \mathrm{~min}$ as a control group.

\section{Oral bacteria test}

20 toothbrushes collected from the 5 groups were immersed in $10 \mathrm{ml}$ of brain heart infusion (BHI, Sigma-Aldrich Co., St. Louis, Mo, USA) broth for $2 \mathrm{~min}$ to suspend and isolate $S$. mutans. For each group, $1 \mathrm{ml}$ was inoculated into the BHI agar solid medium. The colony forming unit (CFU) was measured and quantified after culturing at $37.5^{\circ} \mathrm{C}$ for $24 \mathrm{~h}$.

\section{Statistical analysis}

The data produced in each experiment were analyzed by using the SPSS 19.0 program (SPSS Inc., Chicago, USA). In order to compare the effect among the groups, one-way ANOVA was performed, and Scheffe's method was used as a post hoc test. The statistical significance was set at 0.05 .

\section{Results}

\section{Toothbrush disinfection effect}

The result of the number of bacteria in the mouth is shown in Figure 1, and when the CHX and PVI disinfectants were applied, there were no oral bacteria, thereby indicating the most remarkable antimicrobial effect.

Table 1. Comparison of the amount of oral bacteria in each disinfectant.

\begin{tabular}{ll}
\hline Category & Amount of S. mutans Mean $\Delta E \pm$ SD \\
\hline $0.2 \% \mathrm{CHX}$ & $0 \pm 0^{\mathrm{a}}$ \\
\hline $0.75 \% \mathrm{PVI}$ & $0 \pm 0^{\mathrm{a}}$ \\
\hline Sodium bicarbonate-normal saline & $54.67 \pm 86.08^{\mathrm{a}, \mathrm{b}}$ \\
\hline UV ray toothbrush sterilizer & $17.75 \pm 23.77^{\mathrm{a}, \mathrm{b}}$ \\
\hline D.W (control group) & $970.33 \pm 903.35^{\mathrm{b}}$ \\
\hline${ }^{*}$ The significant difference among the four groups via one-way ANOVA. Different letters $(\mathrm{a}, \mathrm{b})$ presented statistically significant result via Post Hoc Scheffe ("p<0.05).
\end{tabular}

Table 1 shows the results of the group differences regarding the UV toothbrush sterilizer and various disinfectants applied to the toothbrushes. The differences among the 5 groups were statistically significant. Antimicrobial effects of toothbrushes in the experimental groups differed from those in the control group $(\mathrm{p}<0.05)$. After the disinfection with $\mathrm{CHX}$ and PVI, $S$. mutans was not observed as the most obvious antimicrobial effect, followed by UV toothbrush sterilizer and sodium bicarbonate-normal saline and D.W $(p<0.05)$. Comparisons among the groups showed an antimicrobial effect in the order of CHX, PVI, UV toothbrush sterilizer, and sodium bicarbonate-normal saline $(\mathrm{p}<0.05)$. 

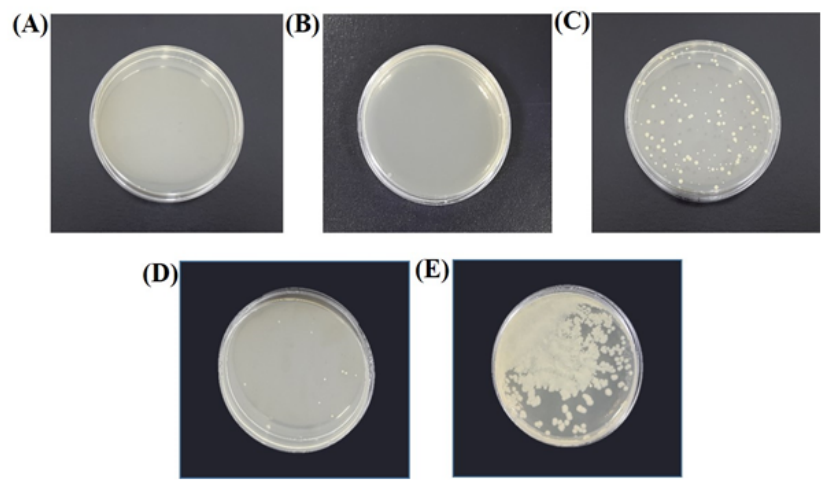

Figure 1. Comparison of the change in the number of oral bacteria according to disinfection. (A) $0.2 \% \mathrm{CHX}$; (B) $7.5 \%$ PVI; (C) Sodium bicarbonate-normal saline; (D) UV toothbrush sterilizer; (E) D.W.

\section{Discussion}

There is a growing interest in oral hygiene management for a healthy oral environment. The toothbrush is the most common tool used to improve the oral health of an individual. Tooth brushing removes dental plaque, massages the gums, and maintains cleanliness in the mouth, thereby playing an important role in the prevention of dental caries and periodontal diseases [18].

The degree of toothbrush contamination varies depending on how the toothbrush was stored after daily use, and the toothbrush can be highly contaminated by microorganisms according to oral conditions, environment, hand hygiene, aerosol contamination, and storage container [19]. The toothbrush is generally stored in the bathroom, and bacteria grow well under such a humid and warm condition [20]. Therefore, the importance of storing and disinfecting the toothbrush after use is further emphasized. In this study, the antimicrobial effect on the toothbrush was investigated, and as a result, the antimicrobial effect was found to be greater in the order of CHX, PVI, UV toothbrush sterilizer, and sodium bicarbonate-normal saline. It was confirmed that various methods of toothbrush disinfection are very helpful in preventing toothbrush infection or cross-infection, and $\mathrm{CHX}$ and PVI disinfectants are the most effective methods for sterilizing harmful microorganisms that remain in the toothbrush.

According to the study conducted by Sogi et al. [21] with $\mathrm{CHX}$ among the toothbrush disinfection methods, immersion in $0.2 \%$ CHX solution for $20 \mathrm{~min}$ per day was found to be sufficient in disinfecting the toothbrush. Another study also reported that immersion in $0.12 \% \mathrm{CHX}$ for $2 \mathrm{~h}$ [22] and $0.2 \%$ $\mathrm{CHX}$ for $20 \mathrm{~h}$ [23] were sufficient in removing $100 \%$ of bacteria in the toothbrush. This study result was consistent with that of the present study. In the present study, $100 \%$ of bacteria were dead after the 10-min immersion in CHX disinfectant. Therefore, it is considered to be effective in disinfecting the toothbrush easily on a daily basis by soaking the toothbrush in CHX for $10 \mathrm{~min}$.
Although there have been studies on the antimicrobial effect of various disinfectants (e.g., CHX, Brushtox, and Periogard) [24] to date, research on the antimicrobial effect of PVI disinfectant on the toothbrush is still lacking. According to the study of Sasannejad [25], when the toothbrush was disinfected with $10 \%$ PVI for $10 \mathrm{~min}$, it showed an antimicrobial effect similar to that of the CHX disinfectant, which was consistent with the result of this study. It means that the PVI disinfectant has an antimicrobial effect on the contaminated toothbrush, and like CHX, PVI solution can be recommended as an appropriate disinfectant for toothbrushes.

In regard to the sterilization effect of the UV toothbrush sterilizer, the initial death of bacteria was different according to the UV toothbrush sterilizer, but it was reported to be $96 \%$ or more when sterilization time was more than $10 \mathrm{~min}$ [26]. According to Chandrdas et al. [27], as a result of evaluating the efficacy of various disinfectants and the UV toothbrush sterilizer, the toothbrushes applied with a UV toothbrush sterilizer for $7 \mathrm{~min}$ showed the lowest reduction in oral bacteria except for the control group. The effect of a UV toothbrush sterilizer has not yet been clearly identified until now. The effect of a UV toothbrush sterilizer was different according to the time of application. In this study, since the application time of the toothbrush was set to $5 \mathrm{~min}$ and $30 \mathrm{~s}$ according to the instruction of the manufacturer, a high antimicrobial effect was not shown, as compared to the chemical disinfectants (CHX and PVI). However, it was confirmed that the use of a UV toothbrush sterilizer had an effect on the death of bacteria. It is expected that a high antimicrobial effect will be shown if the application time is increased for more than $10 \mathrm{~min}$.

Although sodium bicarbonate-normal saline solution has been reported to be a suitable mouth rinse with less discomfort in order to prevent oral infection in patients with stomatitis or acute leukemia, microbial growth inhibition or antimicrobial effects have not been found [28]. Goodman [29] reported that sodium bicarbonate-normal saline does not inhibit microbes, but instead, it promotes healing of oral wounds and relieves pain. However, this study showed that sodium bicarbonatenormal saline inhibited microbial growth of oral bacteria. Further studies on sodium bicarbonate-normal saline are deemed necessary in the future.

Cobb [30] reported that toothbrushes were the cause of repeated infections in the mouth. It is necessary to recognize the importance of proper toothbrush disinfection so as to ensure a healthy oral environment, urge the general public in recognizing the necessity of toothbrush disinfection in order to prevent oral infections due to bacteria in the toothbrush, and implement a simple and efficient disinfection method after tooth brushing. Based on this, it is important for dental hygienists to educate patients about toothbrush disinfection and motivate them on proper toothbrush storage, so they can develop a habit of toothbrush disinfection. 


\section{Conclusion}

The purpose of this study is to investigate the antimicrobial effect of the UV toothbrush sterilizer and various disinfectants on the toothbrush. Toothbrush disinfection must be done continuously at an economical cost. This has an important implication in that toothbrush disinfection can prevent crossinfection. Based on the results of this study, we recommend the use of $0.2 \% \mathrm{CHX}$ and $7.5 \%$ PVI disinfectants as the most recommended disinfection methods for toothbrush disinfection.

\section{References}

1. Schenkein HA, Burmeister JA, Koertge TE, Brooks CN, Best AM, Moore LVH, Moore WEC. The influence of race and gender on periodontal microflora. J Periodont Res 1993; 64: 292-296.

2. Bay I, Kardel KM, Skaugaard MR. Quantitative evaluation of plaque removing ability of different type of toothbrush. J Periodontol 1967; 38: 526-533.

3. Duarte CA, Marcondes PC, Rayel AT. Transmissibilidade da microbiota bucal em humanos: repercussão sobre o dente e o periodonto. Rev Period 1995; 1: 211-216.

4. Glass RT. The infected toothbrush, the infected denture, and transmission of disease: A review. Compendium 1992; 13: 592-598.

5. Coutinho PG, Bittar P, Ditterich RG, Rastelli MC, Romanelli MCMOV, Wambier DS. Analise do acondicionamento e condicoes de escovas dentais utilizadas por pre-escolares. Rev Odonto Cienc 2007; 22: 335-339.

6. Jeong YK, Seong YR, Cho KS, Seong HK, Kim JB. Bacteriological contamination of home toothbrusher and hygiene improvement. J Korean Acad Dent Health 1992; 16: 147-155.

7. Bonten MJ, Hayden MK, Nathan C, van Voorhis J, Matushek M, Slaughter S, Rice T, Weinstein RA. Epidemiology of colonisation of patients and environment with vancomycin resistant enterococci. Lancet 1996; 348: 1615-1619.

8. Verran J, Leahy-Glimartin AA. Investigation into the microbial contamination of toothbrushes. Microbios 1996; 85: 231-238.

9. Caudry SD, Klitorinos A, Chan EC. Contaminated toothbrushes and their disinfection, J Can Dent Assoc 1995; 61; 511-516.

10. Taji SS, Rogers AH. ADRF Trebitsch Scholarship. The microbial contamination of toothbrushes. A pilot study. Aust Dent J 1998; 43: 128-130.

11. Sogi SH, Subbareddy VV, Kiran SN. Contamination of toothbrush at different time intervals and effectiveness of various disinfecting solutions in reducing the contamination of toothbrush. J Indian Soc Pedod Prev Dent 2002; 20: 81-85.

12. Sogi SH, Subbareddy VV, Kiran SN. Contamination of toothbrush at different time intervals and effectiveness of various disinfecting solutions in reducing the contamination of toothbrush. J Indian Soc Pedod Prev Dent 2002; 20: 81-85.

13. Caudry SD, Klitorinos A, Chan ECS. Contaminated toothbrushes and their disinfection. J Can Dent Assoc 1995; 61: 511-516.

14. Neal PR, Rippin JW. The efficacy of a toothbrush disinfectant spray-an in vitro study. J Dent 2003; 31: 153-157.

15. Chibebe Jr J, Pallos D. Avaliação da esterilização de escovas dentais em forno de microondas (estudo in vitro). Rev Biociênc 2001; 7: 39-42.

16. Zolnowski-Casey MARY. An infection control procedure that is the patient's responsibility. J Am Dent Assoc 1998; 129: 616-617.

17. Kim YH, Jun MH, Choi JS. Prevention of chemotherapy induced oral mucositis in patients with acute leukemia by the two oral care protocols. J Korean Acad Adult Nurs 1997; 9: 98-111.

18. Jo BD, Kim DK, Lee BJ. Change in plaque control ability by the professional oral health care program. J Korean Acad Oral Health 2015: 39; 25-36.

19. Gujjari SK, Gujjari AK, Patel PV, Shubhashini PV. Comparative evaluation of ultraviolet and microwave sanitization techniques for toothbrush decontamination. J Int Soc Prev Community Dent 2011; 1: 20-26.

20. Balappanavar AY, Nagesh L, Ankola AV, Tangade PS, Kakodkar P, Varun S. Antimicrobial efficacy of various disinfecting solutions in reducing the contamination of the toothbrush-A comparative study. Oral Health Prev Dent 2009; 7: 137-145.

21. Suma Sogi HP, Subba Reddy VV, Sashi Kiran ND. Contamination of toothbrush at different time intervals and effectiveness of various disinfecting solutions in reducing the contamination of toothbrush. J Indian Soc Pedo Prev Dent 2002; 20: 81-85.

22. Aysegul O, Elgin IE, Gulcin A, Nedim S. The efficacy of chlorhexidine sprays vs mouthwash in the microbial contamination of child toothbrushes. J Dent Child 2007; 74: 177-181.

23. Filho PN. Microbial contamination of tooth brushes and their decontamination. Pediatr Dent 2000; 22: 381-384.

24. Nelson-Filho P, Faria G, da Silva RAB, Rossi MA, Ito IY. Evaluation of the contamination and disinfection methods of toothbrushes used by 24 - to 48 -month-old children. J Dent Child (Chic) 2006; 73: 152-158.

25. Amirabadi F, Saannejad S. Evaluation of the antimicrobial effects of various methods to disinfect toothbrushes contaminated with Streptococcus mutans. Int J Med Res Health 2016; 5: 536-540.

26. Kim JY, Kim JB, Park KH. Sterilizing effects of the ultraviolet ray toothbrush sterilizing devices. J Korean Acad Oral Health 2002; 26: 89-99.

27. Chandrdas D, Jayakumar HL, Chandra M, Katodia L, Sreedevi A. Evaluation of antimicrobial efficacy of garlic, tea tree oil, cetylpyridinium chloride, chlorhexidine, and 
ultraviolet sanitizing device in the decontamination of toothbrush. Indian J Dent 2014; 5: 183-189.

28. Jun MH, Kim YH, Choi JS, Chae SW. Efficacy of three oral gargling protocols for prevention of oral mucositis in acute leukemia during chemotherapy. J Korean Acad Soc Nurs Educ 1997; 3: 193-206.

29. Goodman M. Managing the side effects of chemotherapy. Semin Oncol Nurs 1989; 5: 29-52.

30. Cobb CM. Toothbrushes as a cause of repeated infections of the mouth. Boston Med Surg J 1920; 183: 263-264.

\section{*Correspondence to}

Seoul-Hee Nam

Department of Dental Hygiene

College of Health Sciences

Kangwon National University

Samcheok-Si

Republic of Korea 